ISSN. 2775-4324 (Online)

Journal of Physical Activity and Sports

Volume 2, Nomor 2, Agustus 2021, 180-188

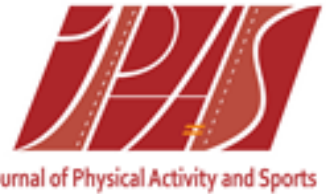

\title{
Modifikasi alat cakram untuk proses pembelajaran
}

\author{
Laras Gita Kinanti' ${ }^{1}$ Utvi Hinda Zhannisa ${ }^{2}$, Tubagus Herlambang ${ }^{3}$ \\ Pendidikan Jasmani Kesehatan dan Rekreasi, Universitas PGRI Semarang \\ Jl. Dr. Cipto Semarang, Jawa Tengah, Indonesia \\ * Coressponding Author. E-mail larasgita095@gmail.com
}

\begin{abstract}
The purpose of this research is to modify a simple disc device for learning physical education. The research method used was the development of Borg \& Gall, namely (1) collecting information, (2) developing the initial form (in the form of a disc tool model), (3) expert validation testing, namely using 1 validation of athletic experts and one physical education learning expert, and small-scale trials using questionnaires and analysis, (4) revision of the first product design, based on the results of experts and small-scale trials (20 students), (5) field trials (48 students), (6) final product revision, (7) the final result of the modification produced through revision of field trials. The results of expert validation were carried out by 2 validities, namely validation in the field of athletic experts and validation of physical education material experts, and the results obtained in each validity were the first for the validation results in the field of athletic experts getting a percentage of $87.6 \%$ calcification (Good), the second for the validation results in the field of Physical Education material experts got a percentage of $83.0 \%$ with the classification (Good). The results of the student questionnaire on a small scale test got a percentage of $86.6 \%$ (good). the results of the questionnaire on large-scale test students got a percentage of $81.8 \%$ (good).The conclusion and advice is that the development of a modified model of disc throwing tools with iron plate waste media can be used as an alternative to discus throwing. With the modification of disc throwing, teachers and students can be helped in learning discusses, students are interested and more active and excited in learning throw the disc.
\end{abstract}

Keywords: Disc, Modification, Media, Physical education

\begin{abstract}
Abstrak
Tujuan dari penelitian ini adalah modifikasi alat cakram sederhana untuk pembelajaran Pendidikan jasmani. Metode penelitian yang digunakan adalah pengembangan dari Borg \& Gall yaitu (1) melakukan pengumpulan informasi, (2) Pengembangan bentuk awal (berupa model alat cakram), (3) uji validasi ahli yaitu menggunakan 1 validasi ahli atletik dan satu ahli pembelajaran penjas, serta uji coba skala kecil dengan menggunakan kuesioner dan dianaisisl, (4) revisi desain produk pertama, berdasarkaan hasil dari ahli dan uji coba skala kecil (20 siswa), (5) uj coba lapangan (48 siswa), (6) revisi produk akhir, (7) hasil akhir modifikasi yang dihasilkan melalui revisi uji coba lapangan. Hasil validasi ahli yang dilakukan oleh 2 validitas yaitu validasi di bidang ahli atletik dan validasi ahli materi penjas, dan hasil yang diperoleh pada masing-masing validitas adalah yang pertama untuk hasil validasi di bidang ahli atletik mendapatkan persentase sebesar 87,6\% kalsifikasi (Baik), yang kedua untuk hasil validasi di bidang ahli materi penjas mendapatkkan persentase sebesar 83,0\% dengan klasifikasi (Baik). Hasil kuesioner siswa pada uji skala kecil mendapatkan persentase sebesar 86,6\% (baik). hasil kuesiner pada siswa uji skala besar mendapatakan persentase sebesar $81,8 \%$ (baik). Kesimpulan dan saram adalah pengembangan model modifikasi alat lempar cakram dengan media limbah plat besi dapat digunakan sebagai alternatif pembelajaran lempar cakram.Dengan adanya modifikasi lempar cakram ini, guru dan siswa dapat terbantu dalam pembelajaran lempar cakram, siswa tertarik dan lebih aktif bergerak dan bersemangat dalam pemblajaran lempar cakram.
\end{abstract}

Kata kunci : Cakram, Modifikasi, Media. Pendidikan Jasmani 


\section{PENDAHULUAN}

Pendidikan jasmani merupakan media untuk mmbina anak agar kelak mereka mampu membuat keputusan terbaik tentang aktivitas jasmani yang dilakukan dan menjalani pola hidup sehat disepanjang hayatnya. Tujuan ini tercapai jika melalui penyediaan pengalaman langsung dan nyata berupa aktivitas jasmani. Aktivitas jasmani itu dapat berupa permainan atau olahraga yang terpilih menurut (Leo Rizky dalam jurnal). Adang Suherman (2000: 22) menyatakan bahwa Penjasorkes merupakan proses pendidikan yang memanfaatkan aktivitas jasmani dan direncanakan secara sistematik bertujuan untuk meningkatkan individu secara organic, neuromuscular, perceptal, kognitif, social, dan emosional. Pendidikan jasmani merupakan bagian dari pendidikan secara keseluruhan, bertujuan untuk mengembangkan aspek kebugaran jasmani, keterampilan gerak, keterampilan berfikir kritis, keterampilan sosial, penalaran, stabilitas emosional, tindakan moral, pola hidup sehat dan pengenalan lingkungan untuk mencapai tujuan pendidikan nasional. (BSNP, 2006: 72).

Pendidikan jasmani disekolah memberi kesemptan kepada siswa untuk terlibat secara langsung dalam aneka pengalaman belajar melalui aktivitas jasmani, bermain, dan aktivitas olahraga secara sistematik, dan terarah sebagai media untuk meningkatkan kemampuan. Gerak sebagai aktivitas jasmani merupakan dasar alami bagi manusia untuk belajar dalam upaya mengenal dunia dan dirinya. Struktur belajar dalam pendidikan jasmani berkaitan dengan bagaimana siswa belajar mencapai tujuan belajar melalui medium aktivitas fisik. Tujuan ideal program pendidikan jasmani bersifat menyeluruh, sebab mencakup bukan hanya aspek fisik tetapi juga aspek lainnya yang mencakup aspek intelektual, emosional, sosial, dan moral dengan maksud kelak anak muda itu menjadi seseorang yang percaya diri, disiplin, sehat, bugar dan hidup bahagia. Rusli Lutan, (2001: 43).Pendidikan tidak dapat terlepaskan dengan keadaan sarana prasarana. Keberdayaan sangat penting di dalam menunjang proses pembelajaran disekolah. Bagi sekolah yang memiliki fasilitas pendidikan jasmani yang memadai akan menambah motivasi guru maupun siswa, karena bisa menunjang kelancaran proses pembelajaran. Namun sebaliknya, jika sekolah-sekolah yang tidak memiliki fasilitas pendidikan jasmani yang layak dan memadai, sarana yang dimiliki juga sangat terbatas, bahkan sering sekali harus mencari lahan kosog atau berdesak-desakan dengan beberapa sekolah lain untuk bisa menggunakan lahan yang ada, maka yang terjadi proses pembelajaran akan berjalan kurang maksimal, sehingga pelaksanaan penidikan jasmani dari hari ke hari hanya begitu-begitu saja dan sering sekali membosankan bagi siswa. Salah satu kendala kurangnya lancarnya pembelajaran pendidikan jasmani di sekolah-sekolah adalah kurang memadainya sarana yang dimiliki oleh sekolah tersebut. Disamping itu juga adanya ketergantungan para guru penjas pada sarana yang standar sesuai degan kurikulum yang ditetapkan. Kedua hal tersebut menyebabkan pola pembelajaran yang kurang variatif dan cenderung membosankan peserta didik Atletik merupakan aktifitas jasmani yang terdiri dari gerakan-gerakan dasar yang dinamis dan harmonis, yaitu jalan, lari, lompat, dan lempar. Atletik juga merupakan sarana untuk pendidikan jasmani dalam upaya meningkatkan kemampuan biomotorik, misalnya kekuatan, daya tahan, kecepatan, 
kelentukan, koordinasi, dan sebagainya. Selain itu juga sebagai sarana untuk pnelitian bagi para ilmuwan (Eddy Purnomo, 2011: ).Lempar cakram adalah salah satu nomor yang terdapat dalam cabang olahraga atletik yang selalu diperlombakan. Baik di dalam penyelenggaraan pesta-pesta olahraga yang bersifat nasional dan internasional maupun dalam kejuaraan atltik sendiri. Dalam cabang olahraga atletik, istilah yang digunakan untuk setiap bagian dari cabang olahraga tersebut adalah "nomor", yaitu : nomor jalan, lari, lompat dan nomor lempar. Lempar atau melempar bagi anak-anak merupakan salah satu dari aktivitas pengembangan kemampuan daya geraknya, yaitu untuk bertindak melakukan suatu bentuk gerakan dengan anggota badanya secara lebih terampil, atau serig juga dikatakan dengan keterampilan mengangkat, memukul, mendorong, dan sebagainya. Oleh karena itu, didalam upaya membina dan meningkatkan aktivitas pengembangan kemampuan daya gerak anak, maka dalam mengajar pendidikan jasmani diajarkan mengenai atletik. Selain itu juga mengenai nomor jalan, nomor lari, dan nomor lompat juga mengenai nomor lmpar yang merupakan suatu alat untuk mendidik anak.Sarana prasarana dalam pembelajaran pendidikan jasmani olahraga an kesehatan (penjasorkes) merupakan salah satu bagian yang strategis dalam pencapaian tujuan pembelajaran. Dengan kata lain, semakin memudahkan guru untuk mencapai tujuan pembelajaran. Begitu sebaliknya, sarana yang tidak lengkap akan menyulitkan guru dalam mencapai tujuan pmblajaran.

Hasil observasi dan wawancara antara penulis dan guru penjasorkes pada pembelajaran lempar cakram pada tanggal 26 Agustus 2019 di MTs NU 31 Hidayatul Mubtadi'in Kalirejo Kecamatan Kangkung Kebupaten Kendal, kondisi di sekolah belum memiliki alat cakram yang digunakan sebagai media pembelajaran lempar cakram, dari kondisi tersebut guru belum dapat menyampaikan materi lempar cakram secara optimal. Sehingga siswa belum pernah mendapatkan materi lempar cakram secara praktik, tetapi guru penjasorkes hanya memberikan gambaran materi lempar cakram. Dari gambaran tersebut, proses pembelajaran lempar cakram menjadi tidak efektif dan akibatnya hasil belajar lempar cakram dinilai kurang optimal. Selain sarana dan prasarana yang belum memadai materi yang dianjurkan kurang menarik, membosankan dan menyulitkan bagi peserta didik. Pada saat materi lempar cakram guru penjasorkes hanya memberikan sedikit pembahasan kepada siswa, tidak pernah memberikan pratik. Hal ini di sebabkan cara mengajarkan lempar cakram berdasarkan tehnik yang sebenarnya tanpa menggunakan modifikasi cakram yang digunakan sebagai sarana pembelajaran, dan dari modifikasi alat tersebut dapat menarik perhatian peserta didik dalam mengikuti pembelajaran lempar cakram. Keadaan ini menunjukkan proses pembelajaran yang masih belum melibatkan peran aktif peserta didik dalam pembelajaran. Dari keadaan ini, peneliti membuat modifikasi alat cakram yang dapat digunakan sebagai alternatif media pembelajaran untuk kegiatan pembelajaran lmpr cakram. Menghadapi hal tersebut di atas, peneliti mencari cara agar dalam pembelajaran lempar cakram mudah dipahami dan dikuasai oleh peserta didik. Mlihat kondisi yang seperti ini maka memodifikasi alat akan sangat membantu memecahkan masalah ini. Peserta didik akan tertantang sekaligus termotivasi karena dengan menggunakan alat yang tepat akan membuat peserta didik mendapatkan hal-hal baru yang 
menyenangkan, pembelajaran yang menarik perhatian peserta didik.Dari beberapa uraian diatas peneliti dapat menyimpulkan, peniliti melakukan modifikasi alat cakram dengan menggunakan limbah plat besi yang di modifikasi untuk keefektifan pembelajaran lempar cakram di MTs NU 31 Hidayatul Mubtadi' in Kalirejo Kecamatan Kangkung Kabupaten Kendal. Demi kelancaran pembelajaran peneliti harus mampu membuat modifikasi yang diinginkan. Dari masalah tersebut peneliti menggunkan metode penelitian R\&D (Research and Devolepment), metode ini dapat membantu untuk kelancaran penelitian.

\section{METODE}

\section{Jenis Penelitian}

Penelitian ini menggunakan metode penelitian dan pengembangan (Research and Development)

\section{Subjek Penelitian}

Subjek uji coba adalah sasaran pemakai produk yaitu siswa MTs NU 31 Hidayatul Mubtadi'in Kalirejo Kangkung Kabupaten Kendal. Uji coba skala kecil akan diujikan pada 20 siswa dan Uji Coba skala besar akan diujikan di pada 48 siswa. Data yang diperoleh dari penelitian ini merupakan data kuantitatif yang akan diubah menjadi kualitatif. Data tersebut digunakan untuk memberi gambaran mengenai kualitas media lempar cakram modifikasi.

\section{Teknik Pengumpulan Data}

Teknik penelitian ini di lakukan untuk mengumpulkan data yang digunakan sebagai dasar untuk menetapkan kelayakan produk yang di kembangkan peneliti. Tahap-tahap dalam uji coba produk ini antara lain: (1) menetapkan desain uji coba, (2) menetapkan subyek uji coba, (3) menetapkan jenis data, (4) menetapkan instrumen, (5) teknik analisi data.

\section{Instrument Data Penelitian}

Instrumen yang digunakan untuk mengumpulkan data pada penelitian ini berupa angket, dan pedoman wawancara. Angket digunakan untuk mengetahui kualitas produk yang dihasilkan. Instrumen berupa wawancara dipakai sebagai alat pengumpul data dari para ahli sehubungan dengan kritik,saran dan masukan - masukan yang bermanfaat bagi kualitas produk tersebut. Sebelum para ahli dan subyek uji coba mengisi angket untuk pengambilan data dijelaskan terlebih dahulu beberapa cara pengisian angket.

\section{HASIL DAN PEMBAHASAN}

Bagian ini memuat hasil atau data penelitian, analisis data penelitian, jawaban dari pertanyaaan penelitian, dan analisis terhadap temuan selama penelitian. 


\section{Sub dari Pembahasan}

Beberapa prosedur pengembangan yang dikemukakan oleh beberapa ahli, salah satunya oleh

Sugiyono (2012:409). Pada penelitian pengembangan ini mengacu pada prosedur penelitian pengembangan menurut Sugiyono yang disesuaikan dengan kebutuhan peneliti. Prosedur penelitian pegembangan menurut Sugiyono dapat dilihat sebagai berikut :

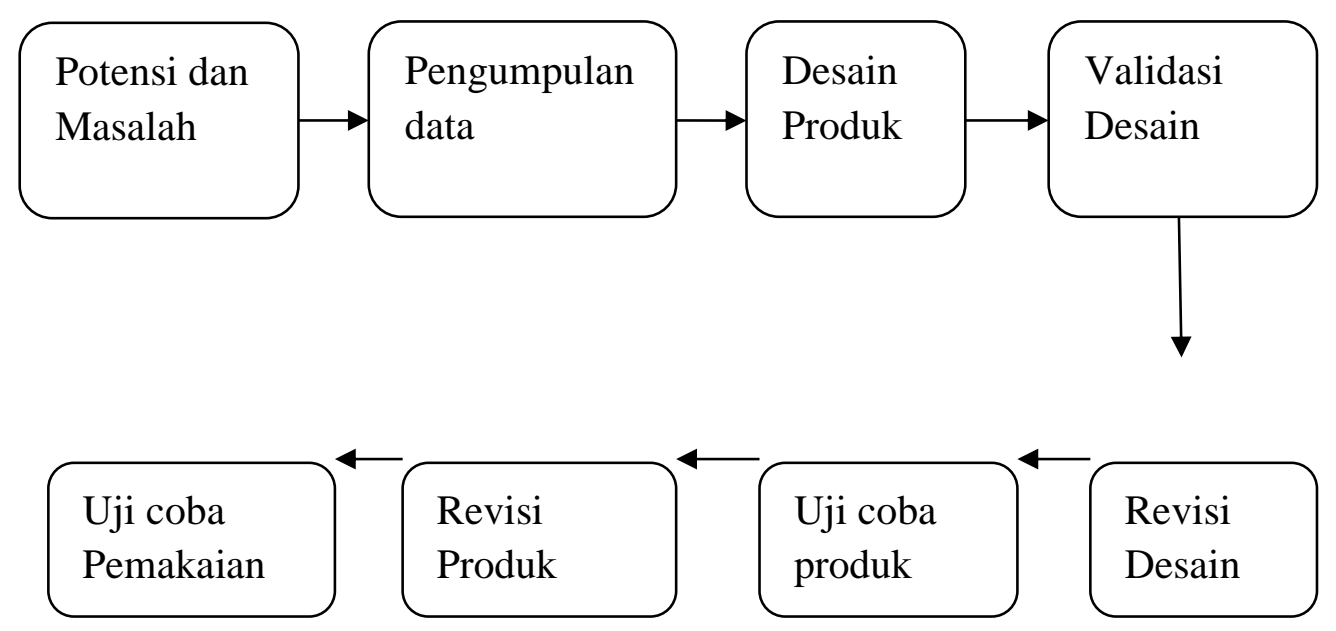

Gambar 1. Prosedur Penelitian Pengembangan

Sumber : (Sugiyono, $2012: 409)$

Tabel 1. Hasil Validasi Ahli Media Pembelajaran Atletik

\begin{tabular}{|c|c|c|c|c|c|c|c|c|c|c|c|c|c|c|c|c|}
\hline \multirow{2}{*}{ Skor } & \multicolumn{13}{|c|}{ Nomor Item } & \multirow{2}{*}{$\mathbf{J m l}$} & \multirow[t]{2}{*}{$\%$} & \multirow[t]{2}{*}{ Ket } \\
\hline & 1 & 2 & 3 & 4 & 5 & 6 & 7 & 8 & 9 & 10 & 11 & 12 & 13 & & & \\
\hline Skor MAX & 5 & 5 & 5 & 5 & 5 & 5 & 5 & 5 & 5 & 5 & 5 & 5 & 5 & 57 & $87,6 \%$ & Baik \\
\hline Skor MIN & 1 & 1 & 1 & 1 & 1 & 1 & 1 & 1 & 1 & 1 & 1 & 1 & 1 & & & \\
\hline $\begin{array}{c}\text { Hasil } \\
\text { Jawaban }\end{array}$ & 4 & 3 & 5 & 5 & 4 & 5 & 5 & 4 & 5 & 4 & 5 & 4 & 4 & & & \\
\hline
\end{tabular}

Tabel 2. Hasil Validasi Ahli Penjas

\begin{tabular}{|c|c|c|c|c|c|c|c|c|c|c|c|c|c|c|c|c|}
\hline \multirow[t]{2}{*}{ Skor } & \multicolumn{13}{|c|}{ Nomor Item } & \multirow[t]{2}{*}{ Jml } & \multirow[t]{2}{*}{$\%$} & \multirow[t]{2}{*}{ Ket } \\
\hline & $\mathbf{1}$ & 2 & 3 & 4 & 5 & 6 & 7 & 8 & 9 & 10 & 11 & 12 & 13 & & & \\
\hline $\begin{array}{l}\text { Skor } \\
\text { MAX }\end{array}$ & 5 & 5 & 5 & 5 & 5 & 5 & 5 & 5 & 5 & 5 & 5 & 5 & 5 & 54 & $83,0 \%$ & Baik \\
\hline $\begin{array}{l}\text { Skor } \\
\text { MIN }\end{array}$ & 1 & 1 & 1 & 1 & 1 & 1 & 1 & 1 & 1 & 1 & 1 & 1 & 1 & & & \\
\hline $\begin{array}{c}\text { Hasil } \\
\text { Jawaban }\end{array}$ & 4 & 4 & 3 & 4 & 4 & 4 & 5 & 4 & 5 & 4 & 5 & 4 & 4 & & & \\
\hline
\end{tabular}


Tabel 3. Hasil Rekapitulasi (Data Analisis Hasil Uji Coba Skala Kecil N=15)

\begin{tabular}{|c|c|c|c|c|c|c|c|c|c|c|c|c|c|c|c|}
\hline \multirow[t]{3}{*}{ NO } & \multirow[t]{3}{*}{ NAMA } & \multicolumn{13}{|c|}{ ASPEK DAN INDIKATOR } & \multirow[t]{3}{*}{ Total } \\
\hline & & \multicolumn{4}{|c|}{ Aspek Materi } & \multicolumn{5}{|c|}{ Aspek Produk } & \multicolumn{4}{|c|}{$\begin{array}{c}\text { Aspek Kebutuhan } \\
\text { Pembelajaran }\end{array}$} & \\
\hline & & 1 & 2 & 3 & 4 & 1 & 2 & 3 & 4 & 5 & 1 & 2 & 3 & 4 & \\
\hline 1 & AT & 4 & 5 & 4 & 4 & 4 & 5 & 4 & 5 & 4 & 4 & 5 & 4 & 5 & 57 \\
\hline 2 & $\mathrm{BJ}$ & 4 & 5 & 4 & 5 & 5 & 4 & 5 & 4 & 5 & 4 & 5 & 4 & 5 & 59 \\
\hline 3 & $\mathrm{AF}$ & 4 & 5 & 5 & 4 & 5 & 5 & 4 & 5 & 5 & 5 & 4 & 4 & 5 & 60 \\
\hline 4 & LM & 4 & 5 & 5 & 4 & 4 & 5 & 5 & 5 & 5 & 4 & 4 & 5 & 4 & 59 \\
\hline 5 & QD & 4 & 5 & 5 & 4 & 5 & 5 & 4 & 5 & 5 & 5 & 4 & 4 & 5 & 60 \\
\hline 6 & SA & 4 & 4 & 4 & 5 & 4 & 5 & 4 & 4 & 4 & 4 & 4 & 4 & 4 & 54 \\
\hline 7 & $\mathrm{ZY}$ & 3 & 4 & 3 & 5 & 4 & 5 & 5 & 4 & 4 & 5 & 4 & 3 & 5 & 54 \\
\hline 8 & AS & 5 & 4 & 4 & 4 & 5 & 5 & 5 & 4 & 4 & 5 & 4 & 3 & 4 & 56 \\
\hline 9 & ES & 3 & 5 & 4 & 5 & 4 & 5 & 5 & 5 & 4 & 4 & 3 & 3 & 5 & 55 \\
\hline 10 & RS & 4 & 4 & 5 & 5 & 4 & 4 & 4 & 4 & 5 & 4 & 4 & 3 & 4 & 54 \\
\hline 11 & $\mathrm{AF}$ & 4 & 5 & 4 & 4 & 5 & 5 & 5 & 5 & 5 & 5 & 4 & 4 & 4 & 59 \\
\hline 12 & NF & 4 & 5 & 4 & 4 & 5 & 5 & 5 & 5 & 5 & 5 & 4 & 4 & 4 & 59 \\
\hline 13 & SJ & 4 & 5 & 5 & 5 & 4 & 5 & 4 & 5 & 4 & 5 & 5 & 4 & 4 & 59 \\
\hline 14 & DR & 4 & 5 & 5 & 4 & 4 & 5 & 5 & 5 & 5 & 4 & 4 & 5 & 4 & 59 \\
\hline 15 & TS & 4 & 5 & 5 & 5 & 4 & 5 & 3 & 5 & 4 & 5 & 4 & 4 & 4 & 57 \\
\hline 16 & SN & 3 & 5 & 4 & 5 & 4 & 5 & 4 & 3 & 4 & 4 & 3 & 3 & 5 & 52 \\
\hline 17 & LK & 5 & 4 & 4 & 4 & 4 & 4 & 4 & 4 & 5 & 3 & 5 & 5 & 4 & 55 \\
\hline 18 & SC & 5 & 4 & 3 & 4 & 5 & 4 & 3 & 4 & 4 & 4 & 3 & 4 & 4 & 51 \\
\hline 19 & $\mathrm{MU}$ & 4 & 4 & 4 & 4 & 5 & 4 & 3 & 5 & 5 & 4 & 4 & 3 & 4 & 53 \\
\hline 20 & SN & 4 & 5 & 3 & 5 & 5 & 5 & 3 & 5 & 4 & 4 & 3 & 4 & 4 & 54 \\
\hline \multicolumn{2}{|c|}{ Jumlah } & 80 & 93 & 84 & 89 & 89 & 95 & 84 & 91 & 90 & 87 & 80 & 77 & 87 & 1126 \\
\hline
\end{tabular}

Tabel 5. Daftar Jawaban Kuesioner Siswa Uji Coba Skala Besar (N=48)

NO NAMA
ASPEK DAN INDIKATOR

\section{Aspek Materi Aspek Produk Aspek Kebutuhan}

Total

Pembelajaran

\begin{tabular}{|c|c|c|c|c|c|c|c|c|c|c|c|c|c|c|c|}
\hline & & & & & & & & & & & \\
\hline & & 1 & 2 & 3 & 4 & 1 & 2 & 3 & 4 & 5 & 1 & 2 & 3 & 4 & \\
\hline 1 & AN & 3 & 4 & 3 & 5 & 5 & 3 & 3 & 4 & 3 & 4 & 4 & 4 & 4 & 49 \\
\hline 2 & AS & 5 & 4 & 4 & 4 & 5 & 5 & 5 & 4 & 4 & 5 & 4 & 3 & 4 & 56 \\
\hline 3 & AJ & 4 & 4 & 3 & 3 & 5 & 4 & 4 & 3 & 3 & 3 & 4 & 4 & 5 & 49 \\
\hline 4 & BB & 4 & 4 & 4 & 4 & 4 & 4 & 4 & 3 & 3 & 3 & 3 & 3 & 3 & 46 \\
\hline 5 & BA & 4 & 4 & 4 & 3 & 3 & 4 & 5 & 5 & 5 & 4 & 3 & 4 & 4 & 52 \\
\hline 6 & EB & 3 & 5 & 4 & 5 & 4 & 5 & 5 & 5 & 4 & 4 & 3 & 3 & 5 & 55 \\
\hline 7 & IN & 4 & 4 & 4 & 5 & 5 & 5 & 5 & 5 & 4 & 4 & 5 & 4 & 5 & 59 \\
\hline 8 & IP & 4 & 4 & 4 & 4 & 4 & 4 & 5 & 5 & 5 & 5 & 4 & 4 & 5 & 57 \\
\hline 9 & LH & 5 & 4 & 4 & 4 & 4 & 4 & 4 & 4 & 5 & 3 & 5 & 5 & 4 & 55 \\
\hline
\end{tabular}


$\begin{array}{llllllllllllllll}10 & \mathrm{HN} & 5 & 4 & 4 & 3 & 3 & 3 & 3 & 4 & 5 & 3 & 5 & 4 & 3 & 49\end{array}$

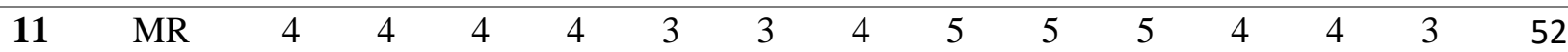

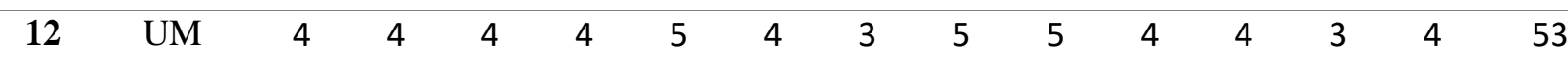

$\begin{array}{llllllllllllllll}13 & \mathrm{Al} & 4 & 3 & 3 & 4 & 5 & 5 & 5 & 3 & 4 & 5 & 3 & 4 & 5 & 53\end{array}$

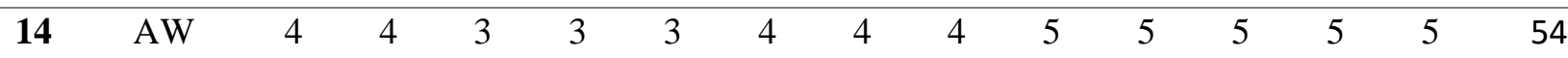

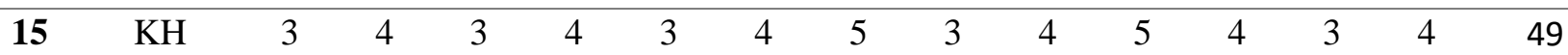

$\begin{array}{llllllllllllllll}16 & \text { IK } & 4 & 3 & 4 & 4 & 4 & 5 & 5 & 4 & 4 & 3 & 3 & 4 & 3 & 50 \\ 17 & \text { ZY } & 3 & 4 & 3 & 5 & 4 & 5 & 5 & 4 & 4 & 5 & 4 & 3 & 5 & 54\end{array}$

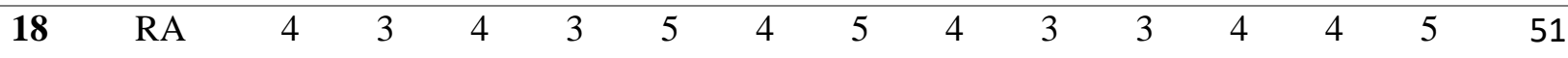

$19 \begin{array}{rllllllllllllll}\mathrm{RN} & 4 & 4 & 5 & 5 & 4 & 4 & 4 & 4 & 5 & 4 & 4 & 3 & 4 & 54\end{array}$

$\begin{array}{llllllllllllllll}20 & \mathrm{RR} & 4 & 4 & 4 & 3 & 4 & 5 & 5 & 5 & 5 & 5 & 4 & 3 & 4 & 55\end{array}$

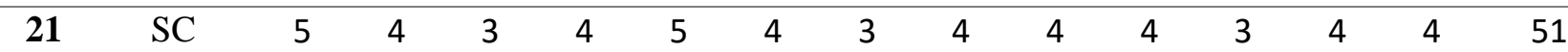

$\begin{array}{lllllllllllllllll}22 & \text { SN } & 3 & 5 & 4 & 5 & 4 & 5 & 4 & 3 & 4 & 4 & 3 & 3 & 5 & 52\end{array}$

$\begin{array}{llllllllllllllll}23 & \mathrm{SA} & 5 & 5 & 5 & 4 & 5 & 4 & 4 & 4 & 5 & 5 & 4 & 4 & 5 & 59\end{array}$

$\begin{array}{llllllllllllllll}24 & \mathrm{NK} & 5 & 5 & 5 & 4 & 4 & 4 & 3 & 3 & 4 & 3 & 4 & 5 & 3 & 52\end{array}$

$\begin{array}{llllllllllllllll}\mathbf{2 5} & \mathrm{HH} & 4 & 5 & 3 & 5 & 5 & 5 & 3 & 5 & 4 & 4 & 3 & 4 & 4 & 54 \\ \mathbf{2 6} & \mathrm{SY} & 4 & 4 & 4 & 5 & 4 & 5 & 4 & 4 & 4 & 4 & 4 & 4 & 4 & 54\end{array}$

$\begin{array}{lllllllllllllllll}27 & \text { WA } & 4 & 4 & 3 & 4 & 3 & 5 & 5 & 5 & 5 & 5 & 4 & 5 & 3 & 55\end{array}$

$\begin{array}{llllllllllllllll}\mathbf{2 8} & \mathrm{AN} & 4 & 5 & 5 & 3 & 4 & 5 & 4 & 5 & 2 & 3 & 3 & 3 & 3 & 49\end{array}$

$\begin{array}{llllllllllllllll}29 & \text { TH } & 4 & 5 & 4 & 4 & 4 & 5 & 4 & 5 & 4 & 4 & 5 & 4 & 5 & 57\end{array}$

$\begin{array}{llllllllllllllll}30 & \mathrm{AA} & 4 & 3 & 4 & 3 & 4 & 4 & 3 & 5 & 4 & 5 & 5 & 5 & 5 & 54\end{array}$

\begin{tabular}{lllllllllllllllll}
\hline 31 & AP & 5 & 5 & 3 & 5 & 5 & 3 & 4 & 5 & 4 & 4 & 3 & 2 & 4 & 52
\end{tabular}

\begin{tabular}{llllllllllllllll}
\hline 32 & $\mathrm{AD}$ & 3 & 4 & 2 & 3 & 4 & 3 & 4 & 5 & 5 & 5 & 5 & 5 & 4 & 52
\end{tabular}

$\begin{array}{llllllllllllllll}33 & \mathrm{AZ} & 4 & 5 & 4 & 4 & 5 & 5 & 5 & 5 & 5 & 5 & 4 & 4 & 4 & 59\end{array}$

$\begin{array}{llllllllllllllll}34 & \text { BJ } & 4 & 5 & 4 & 5 & 5 & 4 & 5 & 4 & 5 & 4 & 5 & 4 & 5 & 59\end{array}$

$\begin{array}{llllllllllllllll}35 & \mathrm{CA} & 4 & 4 & 3 & 4 & 3 & 4 & 4 & 5 & 3 & 5 & 3 & 4 & 5 & 51\end{array}$

$\begin{array}{llllllllllllllll}36 & \text { DT } & 4 & 4 & 5 & 4 & 4 & 5 & 5 & 5 & 5 & 4 & 4 & 5 & 4 & 58\end{array}$

$\begin{array}{llllllllllllllll}37 & \text { LM } & 4 & 5 & 5 & 4 & 4 & 5 & 5 & 5 & 5 & 4 & 4 & 5 & 4 & 59\end{array}$

$\begin{array}{llllllllllllllll}38 & \text { RH } & 2 & 3 & 3 & 4 & 2 & 4 & 3 & 4 & 3 & 4 & 3 & 4 & 5 & 44\end{array}$

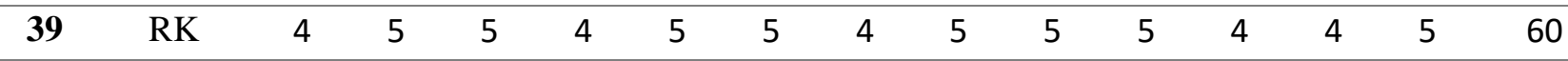

$\begin{array}{llllllllllllllll}40 & \mathrm{DV} & 2 & 3 & 3 & 4 & 3 & 4 & 3 & 4 & 3 & 3 & 3 & 4 & 5 & 44\end{array}$

$\begin{array}{llllllllllllllll}41 & \text { QB } & 4 & 5 & 5 & 4 & 5 & 5 & 4 & 5 & 5 & 5 & 4 & 4 & 5 & 60\end{array}$

\begin{tabular}{llllllllllllllll}
\hline 42 & NI & 4 & 5 & 4 & 4 & 5 & 5 & 5 & 5 & 5 & 5 & 4 & 4 & 4 & 59
\end{tabular}

$\begin{array}{llllllllllllllll}43 & \text { JM } & 4 & 5 & 5 & 5 & 4 & 5 & 4 & 5 & 4 & 5 & 5 & 4 & 4 & 59\end{array}$

$\begin{array}{llllllllllllllll}44 & \text { MF } & 5 & 4 & 4 & 4 & 4 & 5 & 3 & 5 & 4 & 5 & 3 & 4 & 5 & 55\end{array}$

$\begin{array}{llllllllllllllll}45 & \text { TY } & 4 & 5 & 5 & 5 & 4 & 5 & 3 & 5 & 4 & 5 & 4 & 4 & 4 & 57\end{array}$

$\begin{array}{llllllllllllllll}46 & \text { TO } & 2 & 3 & 3 & 4 & 3 & 4 & 3 & 5 & 2 & 4 & 3 & 4 & 5 & 45\end{array}$

$\begin{array}{llllllllllllllll}47 & \mathrm{WW} & 3 & 3 & 3 & 4 & 2 & 4 & 3 & 3 & 3 & 4 & 2 & 4 & 5 & 43\end{array}$

\begin{tabular}{llllllllllllllll}
\hline $\mathbf{4 8}$ & WL & 3 & 4 & 3 & 4 & 4 & 5 & 4 & 4 & 3 & 4 & 3 & 4 & 5 & 50
\end{tabular} $\begin{array}{lllllllllllllll}\text { Jumlah } & 186 & 200 & 184 & 195 & 195 & 210 & 196 & 210 & 198 & 203 & 183 & 188 & 207 & 2555\end{array}$ Jumlah nilai : Jumlah maximum x $100(2555: 3120$ x $100 \%=81,8 \%)$. 


\section{KESIMPULAN}

Berdasarkan hasil penelitian dan pembahasan yang telah diuraikan sebelumnya maka dapat diambil kesimpulan dari penelitian sebagai berikut :

Hasil pengambilan data pada uji coba lapangan yang dilakukan di MTs NU 31 Hidayatul Mubtadi' in yang berjumlah 48 siswa, didapatkan persentase hasil analisis data produk media modifikasi lempar cakram sejumlah 86,6\% untuk uji skala kecil sedangkan uji skala besar diperoleh hasil sejumlah 81,8\% sehingga dapat disimpulkan bahwa modifikasi alat cakram diktegorikan "baik" dan layak untuk digunakan. Dengan adanya modifikasi lempar cakram ini, guru dan siswa dapat terbantu dalam pembelajaran lempar cakram, siswa tertarik dan lebih aktif bergerak dan bersemangat dalam pemblajaran lempar cakram. Siswa merasa senang dan termotivasi dengan adanya mdifikasi lempar cakram, karena selama mereka melakukan pembelajaran lempar cakram guru penjas hanya memberikan materi dikelas tidak pernah malakukan ujian praktek lempar cakram karena terbatasnya sarana prasarana khususnya di nomor atletik lempar cakram.

Dengan demikian, baik dari uji coba skala kecil dan uji coba skala besar, model modifikasi media cakram dapat digunakan sebagai alternatif pembelajaran lempar cakram dalam meningkatkan hasil pembelajaran untuk siswa kelas XI MTs NU 31 Hidayatul Mubtadi'in Kalirejo Kangkung Kendal.

\section{DAFTAR PUSTAKA}

Purnomo, E. (2011). Dasar-Dasar Gerak Atletik. Yogyakarta: Alfamedia.

Khomsin. (2005). ATETIK 1. Semarang: UPT UNNES Press.

Khomsin.(2011).ATETIK 2. Semarang: UPT UNNES Press.

Utami Lilis. (2003). Pengembangan Model Modifikasi Alat Cakram dengan Media Kertas untuk Pembelajaran Penjasorkes pada Siswa Kelas VII SMP HJ Isriati Baiturrahman Kota Semarang Tahun 2014/205. Semarang: tidak diterbitkan.

Widyantoro Ari. (2011). Peningkatan Keterampilan Gerak Dasar Lempar Cakram dengan Modifikasi Alat. Bandar Lampung: tidak diterbitkan.

Ma'muroh. (2015). Tingkat Kreativitas Guru Penjas Dalam Memodifikasi Sarana dan Prasarana Pembelajaran Penjas di SD Negeri Se-Kecamatan Galur Kabupaten Kulon Progo Tahun 2015. Yogyakarta: tidak diterbitkan.

Fred MC Mane. (2000). Dasar-Dasar Atletik. Bandung: Angkasa.

Sugiyono. (2016). Metode Penelitian \& Pengembangan Research and Devolepment. Bandung: Alfabeta.

Debby Suabto Yanuar. (2014). Modifikasi Peluru Berbahan Dasar Serbuk Gergaji Untuk Pembelajaran Tolak Peluru Di Sekolah Dasar. Yogyakarta: tidak diterbitkan.

Sanjaya Aden. (2011). Lempar Cakram Sejarah Teknik dan Peraturan. Diambil dar i: http://aadesanjaya.blogspot.com. (18 Desember 2014) 
Haryati Sri. (2012). Research And Devolepment (R\&D) Sebagai Salah Satu Model Penelitian Dalam Bidang Pendidikan. Jurnal

Mired. (2017). Meningkatkan Lempar Cakram Melalui Media Modifikasi Kayu Cetak Di SD N 05 Terduk Dampak. Pontianak.Jurnal 